\title{
Research on Closed-Loop Supply Chain Network Equilibrium with Two-Type Suppliers, Risk-Averse Manufacturers and Capacity Constraints
}

\author{
Sun $\mathrm{Hao}^{1 *}$, Li Jian ${ }^{2}$, Zhang Gui-Tao ${ }^{1}$ \\ ${ }^{1}$ Qingdao University, School of Management Science and Engineering (China) \\ ${ }^{2}$ Nanjing Agricultural University, College of Engineering (China) \\ *Corresponding author: rivaldoking@gmail.com,telorance61@gmail.com, zhangguitao@gdu.edu.cn
}

\section{Abstract:}

Purpose: The aim of this paper is to investigate the closed-loop supply chain (CLSC) network equilibrium with the consideration of three practical factors: two complementary types of suppliers, risk-averse character of the manufacturer and capacity constraints of the suppliers.

Design/methodology/approach: The equilibrium of various decision makers including the suppliers, the manufacturers, the retailers, the collectors and the demand markets are modeled via finite-dimensional variational inequality, respectively. Then the governing CLSC network equilibrium model is established. The logarithmic-quadratic proximal prediction-correction algorithm is designed to solve the variational inequality model. Numerical examples are given to analyze the impact of return rate, risk-averse degree and capacity constraints on the network equilibrium under different product BOMs.

Findings: With the increase of return rate, the profits of various channel members and the performance of the CLSC system will improve. There is a contradiction between profit maximization and risk minimization for the manufacturers. Moreover, the economic behavior of the CLSC is likely to be limited by the capacity constraints of the suppliers.

Originality/value: Prior to this paper, few papers have addressed with the CLSC network equilibrium considering some practical factors. They assume all the suppliers are identical and 
all the decision-makers are risk neutral. Furthermore, the production capacities of all suppliers are assumed to be infinite or large enough. To fill the gap, this paper examines the influences of two-type suppliers, risk aversion and capacity constraints upon the CLSC network equilibrium.

Keywords: closed-loop supply chain network, variational inequalities, multi-type suppliers, risk averse, capacity constraints

\section{Introduction}

Remanufacturing and closed-loop supply chain (CLSC) management can not only protect environment, promote sustainable development and but also make the firms earn more profits (Guide \& Wassenhove, 2006; Atasu, Guide \& Wassenhove, 2008). Therefore, they have received great attention from the entrepreneurs in recent years. Many famous companies, such as BMW, IBM, Kodak and Fuji Xerox, just to name a few, have established effective endof-life (EOL) product collection and remanufacturing systems besides their traditional production and distribution facility.

Correspondingly, in academia, many scholars also have done plenty of research on CLSC management to guide practice. In general, most of the literature deals with tactical and operational issues, such as reverse channel structure, pricing strategies of new and remanufactured products, inventory control and logistics network design. Savaskan, Bhattacharya and Wassenhove (2004) analyzed the reverse channel choice problem in CLSC and proved that retailer-collection mode is optimal. Shi, Zhang and Sha (2011) developed a mathematical model to maximize the overall profit of the CLSC system by simultaneously determining the selling price, the production quantities for brand-new products and remanufactured products. Golinska and Kawa (2011) provided a framework for management of reverse flow of materials in automotive industry, and utilized agent-based technology to find the optimal solutions for the dynamic network configuration. Zhu and $\mathrm{Xu}$ (2012) built an integrated optimization model for a CLSC network under uncertainty, and solved the model by hybrid genetic algorithm. But they failed to recognize the CLSC as a business process and ignored the important strategic issue of competition.

Under a competitive environment, Majumder and Groenevelt (2001) presented a two-period model of remanufacturing in the face of competition between an original equipment manufacturer (OEM) and a local remanufacturer. Savaskan and Wassenhove (2006) investigated the optimal reverse channel design in a CLSC with one manufacturer and two competing retailers. Research by (Webster \& Mitra 2007; Mitra \& Webster, 2008) examined the impact of take-back laws and government subsidies within an OEM/remanufacturer competitive framework, respectively. Other related research includes Debo, Toktay and Wassenhove (2005), Ferguson and Toktay (2006), Chen and Chang (2012), Örsdemir, Kemahlıŏlu-Ziya and 
Parlaktürk (2014) and so on. Although the literatures lay a solid foundation for future research, they only discuss the competition between an OEM and a remanufacturing or between two retailers who are dealing with a single demand market.

In fact, as we know, the CLSC is likely to have a wider variety of channel members and complex competitive relations. For example, a complete CLSC may have several mutual competitive suppliers, competitive manufacturers, competitive retailers, competitive collectors and several demand markets. As noted in Nagurney, Dong and Zhang (2002), such type of competition could be the main driver of the supply chain profitability and therefore, needs to be analyzed more in depth.

There are a few papers studying the competition among multiple kinds of channel members in reverse supply chain network or CLSC networks. Nagurney and Toyasaki (2005) constructed a multitiered network equilibrium framework for electronic waste recycling using the variational inequality method. Hammond and Beullens (2007) expanded the model of Nagurney and Toyasaki (2005) to build an oligopolistic CLSC network model including manufacturers and demand markets under WEEE legislation. Yang, Wang and Li (2009) used variational inequality method to model the five-echelon CLSC network including suppliers, manufacturers, retailers, recovery centers and consumer markets. Qiang, Ke, Anderson and Dong (2013) established a CLSC network model considering the competition, distribution channel investment and uncertainties. Wakolbinger, Toyasaki, Nowak and Nagurney (2014) formulated the e-waste network flow model as a variational inequality problem to analyze how technical, market, and legislative factors influence the total amount of e-waste that is collected, recycled, exported and (legally and illegally) disposed off.

However, the above mentioned network models didn't consider the case of multi-type suppliers. In reality, the manufacturers need cooperate with many different types of providers, such as multi-type raw material or component suppliers, so the premise that all suppliers are identical may be inappropriate; In addition, most literature assumed the production capacity of all suppliers are infinite or large enough, but in fact the quantity of raw materials supplied to the manufacturers are usually limited by the capacity of the suppliers. Furthermore, the characteristics of decision-makers' risk attitudes are seldom considered in the previous models. To fill the gap, this paper studies the CLSC network equilibrium model with the consideration of three distinct factors: two complementary types of suppliers, capacity constraints of the suppliers and the manufacturers' risk-averse character, then analyzes the impact of these factors on the equilibrium solutions combined with numerical examples and provides several meaningful management insights.

The rest of this paper is organized as follows: in Section 2, we derive the optimality conditions of the various decision-makers by finite-dimensional variational inequality theory and formulate the whole CLSC network' equilibrium model. In Section 3, we present the computational algorithm for solving the Nash equilibrium. We conduct numerical examples and 
sensitivity analysis in Section 4 to generate managerial insights from our model. Finally, conclusions and suggestions for future research are given in section 5 .

\section{Closed-Loop Supply Chain Network Model}

The general CLSC network investigated is illustrated in Figure 1, which consists of the forward supply chain network and the reverse supply chain network. In the forward network, two groups of $J_{1}$ and $J_{2}$ suppliers provide two complementary types of raw materials respectively for $M$ manufacturers who are involved in the production of homogeneous products, which are then shipped to $N$ retailers, who, in turn, sell the products in $K$ demand markets. In the reverse network, I collectors pick up the EOL products from the demand markets, gather, clean and deliver them back to the manufacturers for remanufacturing. In Figure 1, the real lines express the forward transactions between the suppliers and the manufacturers, the manufacturers and the retailers, the retailers and the demand markets; the dashed lines illustrate the reverse transactions between the demand markets and the collectors, the collectors and the manufactures. Moreover, it is assumed the remanufactured products and the new products are indistinguishable. In other words, there are no perceived quality and reliability depreciation of the two kinds of products for the consumers.

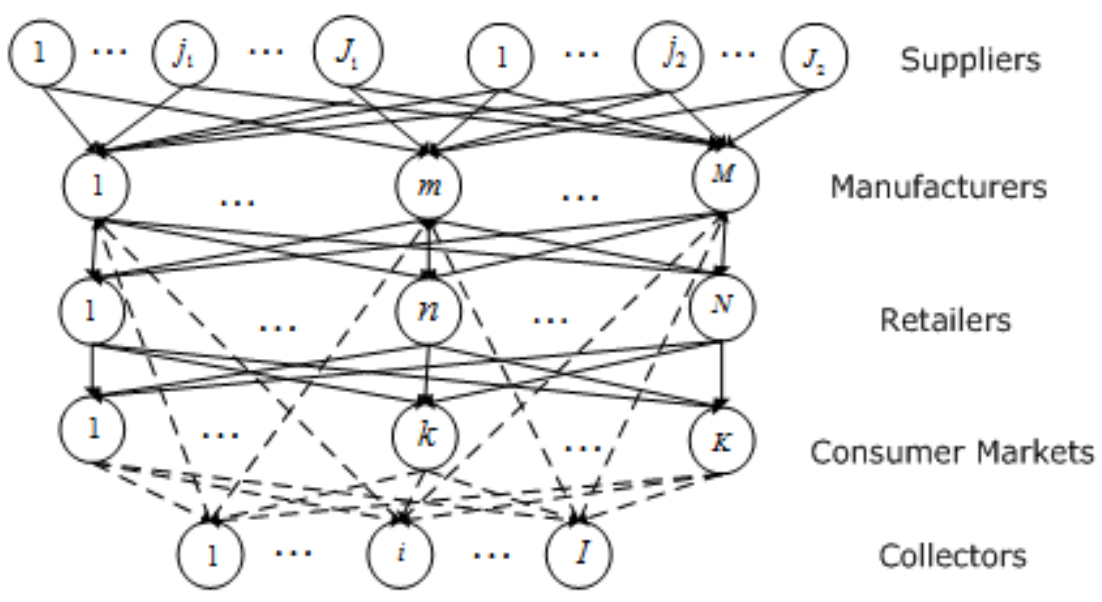

Figure 1. The structure of CLSC network with two-type suppliers

\subsection{The Equilibrium of the Suppliers and their Optimality Conditions}

Let $q_{1 j_{1} m}^{r} \in R_{+}^{M}, q_{2 j_{2} m}^{r} \in R_{+}^{M}$, denote the raw material shipment between a typical supplier $j_{1}, j_{2}$ and a typical manufacturer $m$, and group the shipments between all pairs of suppliers and manufacturers into the column vector $\left(Q^{1}, Q^{2}\right) \in R_{+}^{J_{1} M+J_{2} M}$. Let $f_{1 j_{1}}\left(q_{J_{1}}^{r}\right)$ and $f_{2 j_{2}}\left(q_{J_{2}}^{r}\right)$ denote the production cost of supplier $j_{1}$ and $j_{2}$ respectively, which means the cost of supplier $j_{1}, j_{2}$ depend not only on his own raw material output but also on those of the other suppliers. The transaction cost undertaken by the supplier between supplier $j_{1}, j_{2}$ and manufacturer $m$ is 
denoted by $c_{j_{1} m}\left(q_{1 j_{1} m}^{r}\right), c_{j_{2} m}\left(q_{2 j_{2} m}^{r}\right)$ respectively, and the transaction price associated with supplier $j_{1}, j_{2}$ and manufacturer $m$ is denoted by $\rho_{j_{1} m}^{*}, \rho_{j_{2} m}^{*}$. Let $C_{1 j_{1}}$ and $C_{2 j_{2}}$ represent the upper bound of the production capacity for the 1st-type supplier $j_{1}$ and 2 nd-type supplier $j_{2}$, respectively. Moreover, assume $f_{1 j_{1}}\left(q_{j_{1}}^{r}\right), f_{2 j_{2}}\left(q_{j_{2}}^{r}\right)$ and $c_{j_{1} m}\left(q_{1 j_{1} m}^{r}\right), c_{j_{2} m}\left(q_{2 j_{2} m}^{r}\right)$ are continuous, differentiable and convex functions.

Given the notations and assumptions mentioned above, the profit maximization problem of each supplier $j_{1}$ can be expressed as

$$
\begin{gathered}
\max _{q_{1_{1}}^{r} \geq 0} \pi_{j_{1}}\left(q_{j_{1}}\right)=\sum_{m=1}^{M} \rho_{j_{1} m}^{*} q_{1 j_{1} m}^{r}-f_{1 j_{1}}\left(q_{j_{1}}^{r}\right)-\sum_{m=1}^{M} c_{j_{1} m}\left(q_{1 j_{1} m}^{r}\right) \\
\text { s.t. } q_{1 j_{1}}^{r} \leq C_{1 j_{1}}, \sum_{m=1}^{M} q_{1 j_{1} m}^{r} \leq q_{1 j_{1}}^{r}
\end{gathered}
$$

Equation (1) states that the profit of the 1st-type supplier is equal to sales revenues of raw materials minus the costs associated with production and transactions. The first inequality of constraint set (2) means the production quantity of the 1st-type raw material by the supplier should be no more than the upper bound of his capacity. The second inequality of constraint set (2) means the transaction volumes between the supplier and all the manufacturers must not exceed his production quantity.

The profit maximization problem of each supplier $j_{2}$ can be expressed as

$$
\begin{gathered}
\max _{q_{1 j_{2}}^{r} \geq 0} \pi_{j_{2}}\left(q_{j_{2}}\right)=\sum_{m=1}^{M} \rho_{j_{2} m}^{*} q_{2 j_{2} m}^{r}-f_{2 j_{2}}\left(q_{j_{2}}^{r}\right)-\sum_{m=1}^{M} c_{j_{2} m}\left(q_{2 j_{2} m}^{r}\right) \\
\text { s.t. } q_{2 j_{2}}^{r} \leq C_{2 j_{2}}, \sum_{m=1}^{M} q_{2 j_{2} m}^{r} \leq q_{2 j_{2}}^{r}
\end{gathered}
$$

Similar as Equation (1) and constraint set (2), we can explain Equation (3) and constraint set (4) for the 2nd-type supplier.

Because the same type suppliers compete in a non-cooperative fashion, the optimality conditions for both type of suppliers can be expressed simultaneously using the following variational inequality: determine the optimal solution $\left(q_{J_{1}}^{r^{*}}, q_{J_{2}}^{r^{*}}, Q^{1^{*}}, Q^{2^{*}}\right) \in \Omega^{S}$, satisfying

$$
\begin{aligned}
& \sum_{j_{1}=1}^{J_{1}} \sum_{m=1}^{M}\left[\frac{\partial c_{j_{1} m}\left(q_{1 j_{1} m}^{r}\right)}{\partial q_{1 j_{1} m}^{r}}-\rho_{j_{1} m}^{*}\right] \times\left[q_{1 j_{1} m}^{r}-q_{1 j_{1} m}^{r^{*}}\right]+\sum_{j_{1}=1}^{J_{1}} \frac{\partial f_{1 j_{1}}\left(q_{1 j_{1}}^{*}\right)}{\partial q_{1 j_{1}}} \times\left[q_{1 j_{1}}-q_{1 j_{1}}^{*}\right] \\
&+ \sum_{j_{2}=1}^{J_{2}} \sum_{m=1}^{M}\left[\frac{\partial c_{j_{2} m}\left(q_{2 j_{2} m}^{r}\right)}{\partial q_{2 j_{2} m}^{r}}-\rho_{j_{2} m}^{*}\right] \times\left[q_{2 j_{2} m}^{r}-q_{2 j_{2} m}^{r^{*}}\right]+\sum_{j_{2}=1}^{J_{2}} \frac{\partial f_{2 j_{2}}\left(q_{2 j_{2}}^{*}\right)}{\partial q_{2 j_{2}}} \times\left[q_{2 j_{2}}-q_{2 j_{2}}^{*}\right] \geq 0 \\
& \forall\left(q_{J_{1}}^{r}, q_{J_{2}}^{r}, Q^{1}, Q^{2}\right) \in \Omega^{S}
\end{aligned}
$$

Where $\Omega^{S}=\left\{\left(q_{J_{1}}^{r}, q_{J_{2}}^{r}, Q^{1}, Q^{2}\right) \in R_{+}^{J_{1}+J_{2}+J_{1} M+J_{2} M} \mid q_{1 j_{1}}^{r} \leq C_{1 j_{1}}, q_{2 j_{2}}^{r} \leq C_{2 j_{2}}, \sum_{\mathrm{m}=1}^{M} q_{1 j_{1} m}^{r} \leq q_{1 j_{1}}^{r}, \sum_{\mathrm{m}=1}^{M} q_{2 j_{2} m}^{r} \leq q_{2 j_{2}}^{r}\right\}$ 


\subsection{The Equilibrium of the Manufacturers and their Optimality Conditions}

Each unit of product is made up of $\beta_{1}$ unit of 1st-type raw material and $\beta_{2}$ unit of 2 nd-type raw material, which is the so-called "Bills of Materials (BOM)".

Let $q_{m}$ denote the non-negative production output by raw materials of manufacturer $m$, and group the production output of all manufacturers into the column vector $q \in R_{+}^{M}$. The product shipment between manufacturer $m$ and retailer $n$ is denoted by $q_{m n}$; the product shipments between all pairs of manufacturers and retailers are grouped into a column vector $Q^{3} \in R_{+}^{M N}$. Denote $\rho_{m n}^{*}$ as the price charged for the product by manufacturer $m$ to retailer $n$. The EOL product transaction volume between collector $i$ and manufacturer $m$ is denoted by $q_{i m}$; the EOL product transaction volumes between all pairs of manufacturers and collectors are grouped into a column vector $Q^{4} \in R_{+}^{M I}$. Let $q_{m}^{u}$ denote the quantity of the EOL products that manufacturer $m$ decides to remanufacture, and group all these $q_{m}^{u}$ into the column vector $q^{u}$, then it is straightforward to obtain $q_{m}^{u} \leq \sum_{i=1}^{\mathrm{I}} q_{i m}$. Denote $\rho_{\mathrm{im}}^{*}$ as the price charged for the EOL product by collector $i$ to manufacturer $m$.

Each manufacturer $m$ is face with the production cost of the raw materials $f_{m}(q)$ and the remanufacturing cost of the EOL products $f_{m}^{u}\left(q^{u}\right)$ respectively. Assume these two functions are continuous, differentiable and convex. The transaction cost undertaken by the manufacturer between manufacturer $m$ and retailer $n$ is a function of $c_{m n}=c_{m n}\left(q_{m n}\right)$. Moreover, in order to express competition among manufacturers, it is assumed that $f_{m}(q)$ depends not only on the production output of manufacturer $m$ but also on those of the other manufacturers.

Given the above notations and assumptions, we can express the criterion of profit maximization for manufacturer $m$ as:

$$
\begin{aligned}
& \quad \max \pi_{m}\left(q, q^{u}, Q^{1}, Q^{2}, Q^{3}, Q^{4}\right)=\sum_{n=1}^{N} \rho_{m n}^{*} q_{m n}-f_{m}(q)-\sum_{n=1}^{N} c_{m n}\left(q_{m n}\right)-\sum_{j_{1}=1}^{J_{1}} \rho_{1 j_{1} m}^{*} q_{1 j_{1} m} \\
& \quad-\sum_{j_{2}=1}^{J_{2}} \rho_{2 j_{2} m}^{*} q_{2 j_{2} m}-\sum_{i=1}^{I} \rho_{i m}^{*} q_{i m}-f_{m}^{u}\left(q_{m}^{u}\right) \\
& \text { where } \Omega_{m}^{M}=\left\{\begin{array}{l}
\left.\left(q_{m}, q_{j_{1} m}, q_{j_{2} m}, q_{m n}, q_{m}^{u}, q_{i m}\right) \in R_{+}^{1+J_{1}+J_{2}+N+1+I} \mid \begin{array}{c}
\sum_{n=1}^{N} q_{m n} \leq q_{m}+q_{m}^{u}, \beta_{1} q_{m} \leq \sum_{j_{1}=1}^{J_{1}} q_{1 j_{1} m} \\
\beta_{2} q_{m} \leq \sum_{j_{2}=1}^{J_{2}} q_{2 j_{2} m}, q_{m}^{u} \leq \sum_{i=1}^{I} q_{i m}
\end{array}\right\}
\end{array}\right.
\end{aligned}
$$

Equation (6) indicates that the profit of the manufacturer is equal to sales revenues of new and remanufactured products minus the production and remanufacturing costs, the buy-back costs of EOL products and the transaction costs with the suppliers and the retailers. The first inequality of constraint set (7) means the shipments of products between the manufacturer and all the retailers should be equal to or less than the sum of the production output and the 
remanufacturing output. The second inequality of constraint set (7) means that the manufacturer's production quantity of new products should be constrained by the quantity of 1st-type raw material purchased from the suppliers dividing by the number of the 1st-type raw material in each product according to the BOM. The explanation of the third inequality is similar as the second one. The fourth inequality of constraint set (7) means the quantity of the EOL products that the manufacturer intends to remanufacture is less than or equal to the transaction volumes between him and all the collectors.

Moreover, we assume that with the consideration of the risk associated with purchasing raw materials from the two-type suppliers, shipping the products to the various retailers and obtaining EOL products from the collectors, all the manufacturers are characteristic of risk aversion. Therefore, besides the criterion of profit maximization each manufacturer is concerned with risk minimization. The risk level perceived by a typical manufacturer may be dependent not only on the flows he controls but also upon those controlled by other manufacturers. Hence, the second criterion of manufacturer $m$ can be expressed as (Zsidisin, 2003; Nagurney, Cruz, Dong \& Zhang, 2005):

$$
\min _{q_{j 1 m} \geq 0, q_{j 2 m} \geq 0, q_{m} \geq 0, q_{i m} \geq 0} r_{m}=r_{m}\left(Q^{1}, Q^{2}, Q^{3}, Q^{4}\right), \forall m
$$

Each manufacturer associates a non-negative risk-averse degree $\lambda_{m}$ with the risk minimization criterion (8). Hence, the multi-criterion decision-making problem for manufacturer $m$ can be transformed into a single objective optimization problem (Keeney \& Raiffa, 1993):

$$
\begin{aligned}
& \max U_{m}\left(q, q^{u}, Q^{1}, Q^{2}, Q^{3}, Q^{4}\right)=\sum_{n=1}^{N} \rho_{m n}^{*} q_{m n}-f_{m}(q)-\sum_{n=1}^{N} c_{m n}\left(q_{m n}\right)-\sum_{j_{1}=1}^{J_{1}} \rho_{1 j_{1} m}^{*} q_{j_{1} m} \\
& -\sum_{j_{2}=1}^{J_{2}} \rho_{2 j_{2} m}^{*} q_{j_{2} m}-\sum_{i=1}^{I} \rho_{i m}^{*} q_{i m}-f_{m}^{u}\left(q^{u}\right)-\lambda_{m} r_{m}\left(Q^{1}, Q^{2}, Q^{3}, Q^{4}\right)
\end{aligned}
$$

We presume that the transaction cost functions and the risk functions for each manufacturer are continuous and convex. Because all the manufacturers compete non-cooperatively, the optimal conditions for all the manufacturers can be described as the following variational inequality: determine the optimal $\left(q^{*}, q^{u^{*}}, Q^{1^{*}}, Q^{2^{*}}, Q^{3^{*}}, Q^{4^{*}}\right) \in \Omega^{M}$, satisfying:

$$
\begin{aligned}
& \sum_{m=1}^{M} \frac{\partial f_{m}\left(q^{*}\right)}{\partial q_{m}} \times\left[q_{m}-q_{m}^{*}\right]+\sum_{m=1}^{M} \sum_{n=1}^{N}\left[\frac{\partial c_{m n}\left(q_{m n}^{*}\right)}{\partial q_{m n}}-\rho_{m n}^{*}+\lambda_{m} \frac{\partial r_{m}\left(Q^{1 *}, Q^{2 *}, Q^{3 *}, Q^{4 *}\right)}{\partial q_{m n}}\right] \times\left[q_{m n}-q_{m n}^{*}\right] \\
& +\sum_{m=1}^{M} \sum_{j_{1}=1}^{J_{1}}\left[\rho_{1 j_{1} m}^{*}+\lambda_{m} \frac{\partial r_{m}\left(Q^{1 *}, Q^{2 *}, Q^{3 *}, Q^{4 *}\right)}{\partial q_{1 j^{m}}}\right] \times\left[q_{1 j_{1} m}^{r}-q_{1 j_{1} m}^{r *}\right] \\
& +\sum_{m=1}^{M} \sum_{j_{2}=1}^{J_{2}}\left[\rho_{2 j_{2} m}^{*}+\lambda_{m} \frac{\partial r_{m}\left(Q^{1 *}, Q^{2 *}, Q^{3 *}, Q^{4 *}\right)}{\partial q_{2 j_{2} m}}\right] \times\left[q_{2 j_{2} m}^{r}-q_{2 j_{2} m}^{r *}\right] \\
& +\sum_{m=1}^{M} \sum_{i=1}^{I}\left[\rho_{i m}^{*}+\lambda_{m} \frac{\partial r_{m}\left(Q^{1 *}, Q^{2 *}, Q^{3 *}, Q^{4 *}\right)}{\partial q_{i m}}\right] \times\left[q_{i m}-q_{i m}^{*}\right]+\sum_{m=1}^{M} \frac{\partial f_{m}\left(q^{u *}\right)}{\partial q_{m}^{u}} \times\left[q_{m}^{u}-q_{m}^{u *}\right] \geq 0 \\
& \forall\left(q, q^{u}, Q^{1}, Q^{2}, Q^{3}, Q^{4}\right) \in \Omega^{M}
\end{aligned}
$$


Where $\Omega_{m}^{M}=\left\{\left(q, q^{u}, Q^{1}, Q^{2}, Q^{3}, Q^{4}\right) \in R_{+}^{2 M+J_{1} M+J_{2} M+M N+I M} \mid \begin{array}{c}\sum_{n=1}^{N} q_{m n} \leq q_{m}+q_{m}^{u}, \beta_{1} q_{m} \leq \sum_{j_{1}=1}^{J_{1}} q_{1 j_{1} m} \\ \beta_{2} q_{m} \leq \sum_{j_{2}=1}^{j_{2}} q_{2 j_{2} m}, q_{m}^{u} \leq \sum_{i=1}^{I} q_{i m}\end{array}\right\}$.

\subsection{The Equilibrium of the Retailers and their Optimality Conditions}

The retailers transact with the manufacturers as well as the consumers. Specifically, they need to decide how much to order from the manufactures in order to deal with the demand markets while seeking to maximize their profits.

Let $s_{n}=\sum_{m=1}^{M} q_{m n}$, in turn, denote the total order quantity at retailer $n$ that he obtains from all the manufacturers, and group these purchased amounts into the column vector $s \in R_{+}^{N}$. The retailer $n$ is faced with what we term a handling cost, which may include the display and storage cost associated with the product. Let $c_{n}\left(s_{n}\right)$ denote this cost function and it is continuous, differentiable and convex.

The product shipment between retailer $n$ and demand market $k$ is denoted by $q_{n k}$; the product shipments between all pairs of retailers and demand markets are grouped into a column vector $Q^{5} \in R_{+}^{N K}$. The retailer $n$ has associated transaction costs in regard to transacting with the demand market $k$. Let $c_{n k}\left(q_{n k}\right)$ represent this cost. In addition, the transaction price between retailer $n$ and demand market $k$ is denoted by $\rho_{n k}^{*}$.

For retailer $n$, his maximum profit model is

$$
\begin{aligned}
& \max \pi_{n}\left(Q^{3}, Q^{5}\right)=\rho_{n k}^{*} \sum_{k=1}^{K} q_{n k}-c_{n}\left(s_{n}\right)-\sum_{m=1}^{M} \rho_{m n} q_{m n}-\sum_{k=1}^{K} c_{n k}\left(q_{n k}\right) \\
& \text { where } \Omega_{n}^{R}=\left\{\left(q_{m n}, q_{n k}\right) \in R_{+}^{M+K} \mid s_{n}=\sum_{m=1}^{M} q_{m n}, \sum_{k=1}^{K} q_{n k} \leq \sum_{m=1}^{M} q_{m n}\right\}
\end{aligned}
$$

Equation (11) indicates that the profit of the retailer is equal to sales revenues of new and remanufactured products minus the handling cost, the purchasing costs paid to the manufacturers and the transaction costs with the collectors. The equality in constraint set (12) means that the handling quantity at the retailer's should be equal to the quantity of the products he purchases from all the manufacturers. The inequality in constraint set (12) means that the total sale volumes from the retailer to all the demand markets should be no more than the retailer obtains from all the manufacturers. 
Because all the retailers compete in a non-cooperative fashion, the optimality conditions for all retailers can be expressed as the variational inequality: determine the optimal $\left(Q^{3}, Q^{5}\right) \in \Omega^{R}$, satisfying:

$$
\sum_{k=1}^{k} \sum_{n=1}^{N}\left[\frac{\partial c_{n k}\left(q_{n k}^{*}\right)}{\partial q_{n k}}-\rho_{n k}^{*}\right] \times\left[q_{n k}-q_{n k}^{*}\right]+\sum_{n=1}^{N} \sum_{m=1}^{M}\left[\rho_{m n}^{*}+\frac{\partial c_{n}\left(s_{n}^{*}\right)}{\partial q_{m n}}\right] \times\left[q_{m n}-q_{m n}^{*}\right] \geq 0, \forall\left(Q^{3}, Q^{5}\right) \in \Omega^{R}
$$

Where $\Omega^{R}=\left\{\left(Q^{3}, Q^{5}\right) \in R_{+}^{M N+N K} \mid S_{n}=\sum_{m=1}^{M} q_{m n}, \sum_{k=1}^{K} q_{n k} \leq \sum_{m=1}^{M} q_{m n}\right\}$.

\subsection{The Equilibrium of the Demand Markets}

The consumers in the demand markets transact with the retailers as well as the collectors. Specifically, in the forward supply chain, the consumers need to decide the purchasing quantity of the products and the price they are willing to pay. In the reverse supply chain, the consumers should decide the quantity of EOL products that will be returned to the collectors.

In the forward supply chain, let $\rho_{k}$ denote the price of the products at demand market $k$ and group all these $\rho_{k}$ into a column vector $\rho \in R_{+}^{k}$. Further, denote the demand of the products at demand market $k$ as $d_{k}(\rho)$, which is a monotone decreasing function with respect to the prices of all the markets. In addition, $\hat{c}_{n k}\left(q_{n k}\right)$ is introduced to represent the transaction costs undertaken by the consumers in demand market $k$ while buying the products from retailer $n$. Now we can give the following equations according to the spatial price equilibrium theory (Nagurney et al., 2002).

For retailer $n$,

$$
\rho_{n k}^{*}+\hat{C}_{n k}\left(q_{n k}^{*}\right)\left\{\begin{array}{l}
=\rho_{k}^{*}, \rho_{n k}^{*}>0 \\
\geq \rho_{k}^{*}, \rho_{n k}^{*}=0
\end{array}\right.
$$

and for demand market $k$,

$$
d_{k}\left(\rho^{*}\right)\left\{\begin{array}{l}
=\sum_{n=1}^{N} q_{n k}^{*}, \rho_{k}^{*}>0 \\
\leq \sum_{n=1}^{N} q_{n k}^{*} \rho_{k}^{*}=0
\end{array}\right.
$$

Equation (14) states that if the consumer at demand market $k$ purchases the products from retailer $n$, then the price charged by the retailer for the product plus the unit transaction cost undertaken by the consumer does not exceed the price that the consumer is willing to pay. Equation (15) states that if the price that the consumer at demand market $k$ is willing to pay is positive, and then the quantities purchased of the product should exactly be equal to the demand (Nagurney et al., 2002).

Let $q_{i k}$ denote the EOL product transaction volume between collector $i$ and demand market $k$, and group all these $q_{i k}$ into a column vector $Q^{6} \in R_{+}^{I K}$. In the reverse supply chain, the consumers' behaviors can be characterized by Equation (16) subject to constraint (17). 
Equation (16) means that the customers at demand market $k$ need to choose the quantities of EOL products returned to collector $i$ corresponding to the value of the buy-back price. Herein $\alpha_{k}\left(Q^{6}\right)$ represents the consumer disutility function at demand market $k$ for handing over the EOL products, which is a monotone increasing function depending on the collection quantity. That is, the more EOL products collector $i$ wants to obtain, the higher buy-back price he has to offer. Constraint (17) means that the amount of the EOL products demand market $k$ decides to return should be less than or equal to the amount purchased in the forward supply chain multiply the return ratio $\mu$ (Hammond \& Beullens, 2007; Yang et al., 2009).

$$
\begin{gathered}
\alpha_{\mathrm{k}}\left(Q^{6 *}\right)\left\{\begin{array}{l}
=\rho_{i k}^{*}, \text { if } q_{i k}>0 \\
\leq \rho_{i k}^{*}, \text { if } q_{i k}=0
\end{array}\right. \\
\text { s.t. } \sum_{i=1}^{I} q_{i k} \leq \mu \sum_{n=1}^{N} q_{n k}, \forall k
\end{gathered}
$$

Combining consumer behaviors in both forward and reverse supply chains, the equilibrium conditions for all the demand markets can be expressed as the following variational inequality: determine the optimal $\left(\rho, Q^{5}, Q^{6}\right) \in \Omega^{C}$, satisfying:

$$
\begin{aligned}
& \sum_{k=1}^{K}\left[\sum_{n=1}^{N} q_{n k}^{*}-d_{k}\left(\rho^{*}\right)\right] \times\left(\rho_{k}-\rho_{k}^{*}\right)+\sum_{n=1}^{N} \sum_{k=1}^{K}\left[\rho_{n k}^{*}+\hat{c}_{n k}\left(q_{n k}^{*}\right)-\rho_{k}\right] \times\left[q_{n k}-q_{n k}^{*}\right] \\
& +\sum_{k=1}^{K} \sum_{i=1}^{I}\left[\alpha_{k}\left(Q^{6}\right)-\rho_{i k}^{*}\right] \times\left[q_{i k}-q_{i k}^{*}\right] \geq 0
\end{aligned}
$$

Where $\Omega^{C}=\left\{\left(\rho, Q^{5}, Q^{6}\right) \in R_{+}^{K+N K+I K} \mid \sum_{i=1}^{I} q_{i k} \leq \mu \sum_{n=1}^{N} q_{n k}\right\}$.

\subsection{The Equilibrium of the Collectors and their Optimality Conditions}

The collectors transact with the demand markets as well as the manufacturers. They need to decide the collection quantity of the EOL products from the demand markets and the transaction volumes with the manufacturers.

Let $t_{i}=\sum_{k=1}^{K} q_{i k}$, in turn, denote the total volume of the EOL products at collector $i$ that he obtains from all the demand markets, and group these amounts into the column vector $t \in R_{+}^{I}$. The collectors clean, inspect and classify the EOL products before transacting with the manufacturers. The corresponding processing cost of collector $i$ depends not only on his own but also on those of the other collectors in order to embody competition. Let $c_{i m}\left(q_{i m}\right)$ denote the transaction cost function undertaken by the collector between collectors $i$ and manufacturer $m$. Let $\beta_{3}$ represent the proportion that the quantity of remanufacturable products accounts for that of all the EOL products and satisfy $\beta_{3} \in(0,1]$. Moreover, the government provides the collectors with unit subsidy $v$ for each EOL product collected to 
stimulate the development of reverse logistics. Therefore, collector $i$ can obtain the aggregate subsidy $v \sum_{k=1}^{K} q_{i k}$.

For collector $i$, his maximum profit model is

$$
\begin{gathered}
\max \pi_{i}\left(Q^{4}, Q^{6}\right)=\sum_{m=1}^{M} \rho_{i m}^{*} q_{i m}+v \sum_{k=1}^{K} q_{i k}-\sum_{k=1}^{K} \rho_{i k}^{*} q_{i k}-\sum_{m=1}^{M} c_{i m}\left(q_{i m}\right)-c_{i}(t) \\
\text { s.t. } \sum_{m=1}^{M} q_{i m} \leq \beta_{3} \sum_{k=1}^{K} q_{i k}, \forall i
\end{gathered}
$$

Equation (19) indicates that the profit of the collector is equal to sales revenues of EOL products plus the government subsidies minus the collection costs from the demand markets, the transaction costs with the manufacturers and the processing costs. Constraint (20) means that the transaction volumes between the collector and all the manufacturers should be no more than the amount that he transacts with all the demand markets multiplies the ratio of the remanufacturable EOL products.

Because all the collectors compete in a non-cooperative fashion, the optimality conditions for all collectors can be expressed as the variational inequality: determine the optimal $\left(Q^{4}, Q^{6}\right) \in R_{+}^{M I+I K}$, satisfying:

$$
\begin{aligned}
& \sum_{i=1}^{I} \sum_{m=1}^{M}\left[\frac{\partial c_{i m}\left(q_{i m}^{*}\right)}{\partial q_{i m}}-\rho_{\mathrm{im}}^{*}\right] \times\left[q_{i m}-q_{i m}^{*}\right]+\sum_{i=1}^{I} \sum_{k=1}^{K}\left[\frac{\partial c_{i k}\left(q_{i k}^{*}\right)}{\partial q_{i k}}+\frac{\partial c_{i}\left(t^{*}\right)}{\partial q_{i m}}-v+\rho_{i k}^{*}\right] \times\left[q_{i k}-q_{i k}^{*}\right] \geq 0, \\
& \forall\left(Q^{4}, Q^{6}\right) \in \Omega^{I}
\end{aligned}
$$

Where $\Omega^{I}=\left\{\left(Q^{4}, Q^{6}\right) \in R_{+}^{M I+K I} \mid \sum_{m=1}^{M} q_{i m} \leq \beta_{3} \sum_{k=1}^{K} q_{i k}\right\}$.

\subsection{The Governing Equilibrium Condition of the CLSC Network}

In equilibrium state, the optimality conditions for all suppliers, all manufacturers, all retailers, all collectors and the demand market equilibrium conditions must be satisfied simultaneously. Hence, we can obtain the governing equilibrium condition of the CLSC network.

\section{Theorem}

The governing equilibrium condition of the CLSC network is given by the following variational inequalities: determine $\left(q_{11_{1}}^{*}, q_{1 J_{2}}^{*}, q^{*}, Q^{1 *}, Q^{2 *}, Q^{3 *}, Q^{4 *}, Q^{5 *}, Q^{6 *}, q^{u *}, \rho^{*}\right) \in \Omega$, satisfying: 


$$
\begin{aligned}
& \sum_{j_{1}=1}^{J_{1}} \frac{\partial f_{1 j_{1}}\left(q_{1 j_{1}}^{*}\right)}{\partial q_{1 j_{1}}} \times\left[q_{1 j_{1}}-q_{1 j_{1}}^{*}\right]+\sum_{j_{2}=1}^{J_{2}} \frac{\partial f_{2 j_{2}}\left(q_{2 j_{2}}^{*}\right)}{\partial q_{2 j_{2}}} \times\left[q_{2 j_{2}}-q_{2 j_{2}}^{*}\right] \\
& +\sum_{j_{1}=1}^{J_{1}} \sum_{m=1}^{M}\left[\frac{\partial c_{j_{1} m}\left(q_{1 j_{1} m}^{r *}\right)}{\partial q_{1 j_{1} m}^{r}}+\lambda_{m} \frac{\partial r_{m}\left(Q^{1 *}, Q^{2 *}, Q^{3 *}, Q^{4 *}\right)}{\partial q_{1 j_{1} m}^{r}}\right] \times\left[q_{1 j_{1} m}^{r}-q_{1 j_{1} m}^{r *}\right] \\
& +\sum_{j_{2}=1}^{J_{2}} \sum_{m=1}^{M}\left[\frac{\partial c_{j_{2} m}\left(q_{2 j_{2} m}^{r *}\right)}{\partial q_{2 j_{2} m}^{r}}+\lambda_{m} \frac{\partial r_{m}\left(Q^{1 *}, Q^{2 *}, Q^{3 *}, Q^{4 *}\right)}{\partial q_{2 j_{2} m}^{r}}\right] \times\left[q_{2 j_{2} m}^{r}-q_{2 j_{2} m}^{r *}\right] \\
& +\sum_{m=1}^{M} \frac{\partial f_{m}\left(q^{*}\right)}{\partial q_{m}} \times\left[q_{m}-q_{m}^{*}\right] \\
& +\sum_{m=1}^{M} \sum_{n=1}^{N}\left[\frac{\partial c_{m n}\left(q_{m n}^{*}\right)}{\partial q_{m n}}+\frac{\partial c_{n}\left(s^{*}\right)}{\partial q_{m n}}+\lambda_{m} \frac{\partial r_{m}\left(Q^{1 *}, Q^{2 *}, Q^{3 *}, Q^{4 *}\right)}{\partial q_{m n}}\right] \times\left[q_{m n}-q_{m n}^{*}\right] \\
& +\sum_{m=1}^{M} \sum_{i=1}^{I}\left[\frac{\partial c_{i m}\left(q_{i m}^{*}\right)}{\partial q_{i m}}+\lambda_{m} \frac{\partial r_{m}\left(Q^{1 *}, Q^{2 *}, Q^{3 *}, Q^{* *}\right)}{\partial q_{i m}}\right] \times\left[q_{i m}-q_{i m}^{*}\right] \\
& \sum_{k=1}^{K} \sum_{n=1}^{N}\left[\frac{\partial c_{n k}\left(q_{n k}^{*}\right)}{\partial q_{n k}}+c_{n k}\left(q_{n k}^{*}\right)-\rho_{k}\right] \times\left[q_{n k}-q_{n k}^{*}\right] \\
& +\sum_{i=1}^{I} \sum_{k=1}^{K}\left[\frac{\partial c_{k i}\left(q_{i k}^{*}\right)}{\partial q_{i k}}+\frac{\partial c_{i}\left(t^{*}\right)}{\partial q_{i m}}-v+\alpha_{k}\left(Q^{6 *}\right)\right] \times\left[q_{i k}-q_{i k}^{*}\right] \\
& +\sum_{m=1}^{M} \frac{\partial f_{m}\left(q^{u *}\right)}{\partial q_{m}^{u}} \times\left[q_{m}^{u}-q_{m}^{u *}\right]+\sum_{k=1}^{K}\left[\sum_{n=1}^{N} q_{n k}^{*}-d_{n}\left(\rho^{*}\right)\right] \times\left[\rho_{k}-\rho_{k}^{*}\right] \geq 0 \\
& \forall\left(q_{j_{1}}^{r}, q_{J_{2}}^{r}, Q^{1}, Q^{2}, q, Q^{3}, Q^{4}, Q^{5}, Q^{6}, q^{u}, \rho\right) \in \Omega
\end{aligned}
$$

where $\Omega=\Omega^{s} \times \Omega^{M} \times \Omega^{N} \times \Omega^{C} \times \Omega^{I}$.

\section{Proof}

With some algebraic manipulation, it can be seen that varational inequality (22) and its constraint set is indeed the sum of inequalities (5), (10), (13), (18) and (21) and their constraint sets.

$$
\begin{array}{lcr}
\text { Let } \xi=\left(\xi_{1}, \ldots, \zeta_{j_{1}}, \ldots, \zeta_{J_{1}}\right)^{\top} \in R_{+}^{J_{1}}, & \delta=\left(\delta_{1}, \ldots, \delta_{j_{2}}, \ldots, \delta_{J_{2}}\right)^{\top} \in R_{+}^{J_{2}}, & \varepsilon=\left(\varepsilon_{1}, \ldots, \varepsilon_{j_{1}}, \ldots, \varepsilon_{J_{1}}\right)^{\top} \in R_{+}^{J_{1}}, \\
\psi=\left(\psi_{1}, \ldots, \psi_{j_{2}}, \ldots, \psi_{J_{2}}\right)^{\top} \in R_{+}^{J_{2}}, & \varphi=\left(\varphi_{1}, \ldots, \varphi_{m}, \ldots, \varphi_{M}\right)^{\top} \in R_{+}^{M}, & \chi=\left(\chi_{1}, \ldots, \chi_{m}, \ldots, \chi_{M}\right)^{\top} \in R_{+}^{M}, \\
\omega=\left(\omega_{1}, \ldots, \omega_{m}, \ldots, \omega_{M}\right)^{\top} \in R_{+}^{M}, & \gamma=\left(\gamma_{1}, \ldots, \gamma_{m}, \ldots, \gamma_{M}\right)^{\top} \in R_{+}^{M}, & \eta=\left(\eta_{1}, \ldots, \eta_{n}, \ldots, \eta_{N}\right)^{\top} \in R_{+}^{N},
\end{array}
$$
$\tau=\left(\tau_{1}, \ldots, \tau_{k}, \ldots, \tau_{K}\right)^{\top} \in R_{+}^{K}, \theta=\left(\theta_{1}, \ldots, \theta_{i}, \ldots, \theta_{I}\right)^{\top} \in R_{+}^{I}$ be Lagranian multipliers column vector with respect to the constraints $q_{1 j_{1}}^{r} \leq C_{1 j_{1}}, \quad q_{2 j_{2}}^{r} \leq C_{2 j_{2}}, \quad \sum_{m=1}^{M} q_{j_{1} m} \leq q_{1 j_{1}}^{r}, \sum_{m=1}^{M} q_{j_{2} m} \leq q_{2 j_{2}}^{r}, \quad \beta_{1} q_{m} \leq \sum_{j_{1}=1}^{J_{1}} q_{1 j_{1} m}$, $\beta_{2} q_{m} \leq \sum_{j_{2}=1}^{J_{2}} q_{2 j_{2} m}, \quad q_{m}^{u} \leq \sum_{i=1}^{I} q_{i m}, \quad \sum_{n=1}^{N} q_{m n} \leq q_{m}+q_{m}^{u}, \quad \sum_{k=1}^{K} q_{n k} \leq \sum_{m=1}^{M} q_{m n}, \quad \sum_{i=1}^{I} q_{i k} \leq \mu \sum_{n=1}^{N} q_{n k} \quad$ a nd $\sum_{m=1}^{M} q_{i m} \leq \beta_{3} \sum_{k=1}^{K} q_{i k}$ respectively.

When the governing network model is determined, the endogenous price variables can be retrieved by means of the method introduced in Nagurney et al. (2002) and Yang et al. (2009), 
that is:

$$
\begin{aligned}
& \rho_{j_{1} m}^{*}=\partial c_{j_{1} m}\left(q_{j_{1} m}^{r *}\right) / \partial q_{1 j_{1} m}^{r}+\varepsilon_{j_{1}}^{*} ; \rho_{j_{2} m}^{*}=\partial c_{j_{2} m}\left(q_{2 j_{2} m}^{r *}\right) / \partial q_{2 j_{2} m}^{r}+\psi_{j_{2}}^{*} ; \\
& \rho_{m n}^{*}=\partial c_{m n}\left(q_{m n}^{*}\right) / \partial q_{m n}+\gamma_{m}^{*}+\lambda_{m} \partial r_{m}\left(Q^{1 *}, Q^{2 *}, Q^{3 *}, Q^{4 *}\right) / \partial q_{m n} ; \rho_{n k}^{*}=\partial c_{n k}\left(q_{n k}^{*}\right) / \partial q_{n k}+\eta_{n}^{*} ; \\
& \rho_{i k}^{*}=\alpha_{k}\left(Q^{6}\right)+\tau_{k}^{*} ; \rho_{i m}^{*}=\partial c_{i m}\left(q_{i m}^{*}\right) / \partial q_{i m}+\theta_{i}^{*} .
\end{aligned}
$$

\section{Network Equilibrium Algorithm}

For easy formulation in the following, we group the terms of the multiplication signs in inequality (22) into a column vector

$F(y)=\left\{F_{j_{1}}^{1}, F_{j_{2}}^{2}, F_{j_{1} m}^{3}, F_{j_{2} m}^{4}, F_{m}^{5}, F_{m n}^{6}, F_{i m}^{7}, F_{n k}^{8}, F_{i k}^{9}, F_{m}^{10}, F_{k}^{11}\right\}_{\forall j_{1}, j_{2}, m, n, k, i}$ and introduce

$y=\left\{q_{J_{1}}^{r}, q_{J_{2}}^{r}, Q^{1}, Q^{2}, q, Q^{3}, Q^{4}, Q^{5}, Q^{6}, q^{u}, \rho\right\} \in \Omega$; thus we can rewrite the variational inequality problem (22) in the standard form: determine

$$
\begin{gathered}
y^{*}=\left\{q_{J_{1}}^{r^{*}}, q_{J_{2}}^{r^{*}}, Q^{1 *}, Q^{2 *}, q^{*}, Q^{3 *}, Q^{4 *}, Q^{2 *}, Q^{6 *}, q^{u *}, \rho^{*}\right\} \in \Omega \text {, satisfying: } \\
F(y)^{T} \cdot\left(y-y^{*}\right) \geq 0, \forall y \in \Omega
\end{gathered}
$$

The feasible domain of variational inequality (23) is defined on a polyhedral set of nonnegative orthant. As a consequence, the production capacity constraints induce ineffectiveness of the modified projection method proposed by Korpelevich (1976). Fortunately, the logarithmic-quadratic proximal prediction-correction (LQP-PC) method developed by $\mathrm{He}, \mathrm{Xu}$ and Yuan (2006) can be applied for solving this variational inequality problem. LQP-PC method provides an iterative solution framework that can not only get the optimal solutions and Lagrangian multipliers simultaneously, but also has faster convergence and higher accuracy compared with the modified projection method. Therefore, in this paper we employ LQP-PC method to solve variational inequality (23). To implement LQP-PC method effectively, it is essential to transform the constraint set into the form of partitioned matrix firstly, and then carry out the prediction and correction procedures while adjusting the step size adaptively. We refer the readers to the work such as Meng, Huang and Cheu (2009) to reach a comprehensive understanding.

\section{Numerical Examples}

Now consider a CLSC network which consists of two competitive 1st-type suppliers, two competitive 2nd-type suppliers, two competitive manufacturers, two competitive retailers, two competitive collectors and two demand markets. The raw material cost functions of four suppliers are $f_{11}\left(q_{J_{1}}^{r}\right)=2.5 q_{11}^{r 2}+q_{11}^{r} q_{12}^{r}+q_{11}^{r}, f_{12}\left(q_{J_{1}}^{r}\right)=2.5 q_{12}^{r 2}+q_{11}^{r} q_{12}^{r}+q_{12}^{r}, f_{21}\left(q_{J_{2}}^{r}\right)=2 q_{21}^{r 2}+q_{21}^{r} q_{22}^{r}+q_{21}^{r}$, and $f_{22}\left(q_{J_{2}}^{r}\right)=2 q_{22}^{r 2}+q_{22}^{r} q_{21}^{r}+q_{22}^{r}$, respectively. The transaction cost functions undertaken by the 
suppliers between supplier $j_{1}, j_{2}$ and manufacturer $m$ are $c_{j_{1} m}\left(q_{1 j_{1} m}^{r}\right)=\left(q_{1 j_{1} m}^{r}\right)^{2}+0.1, \forall j_{1}, \forall m$ and $c_{j_{2} m}\left(q_{2 j_{2} m}^{r}\right)=\left(q_{2 j_{2} m}^{r}\right)^{2}+0.1, \forall j_{2}, \forall m$, respectively.

The production cost function of manufacturer $m$ is $f_{m}(q)=4 q_{m}^{2}+q_{m} q_{3-m}+2 q_{m}, m=1,2$.

The remanufacturing cost function of manufacturer $m$ is $f_{1}\left(q^{u}\right)=\left(q_{m}^{u}\right)^{2}+q_{m}^{u} q_{3-m}^{u}+q_{m}^{u}, m=1,2$.

The transactions cost function undertaken by the manufacturer between manufacturer $m$ and retailer $n$ is $c_{m n}\left(q_{m n}\right)=4 q_{m n}^{2}+2.5 q_{m n}, m=1,2 ; n=1,2$.

The transactions cost function undertaken by the collector between collector $i$ and manufacturer $m$ is $c_{i m}\left(q_{i m}\right)=0.5 q_{i m}^{2}+0.5 q_{i m}, i=1,2 ; m=1,2$.

The handling cost of retailer $n$ is $c_{n}\left(s_{n}\right)=8 s_{n}^{2}, n=1,2$.

The processing cost of collector $i$ is $c_{i}(t)=0.2\left(\sum_{k=1}^{2} q_{k i}\right)^{2}+0.1, i=1,2$.

The unit subsidy for each EOL product collected is $v=2$.

The proportion the quantity of remanufacturable products accounts for that of all the EOL products is $\beta_{3}=0.96$.

The transactions cost function undertaken by the demand market between retailer $n$ and demand market $k$ is $\hat{c}_{n k}\left(q_{n k}\right)=q_{n k}+5, n=1,2, k=1,2$.

The consumer disutility function at demand market $k$ is $\alpha_{k}\left(Q_{6}\right)=0.5\left(\sum_{i=1}^{2} \sum_{k=1}^{2} q_{i k}\right)+5$.

The transactions cost function undertaken by the retailer between retailer $n$ and demand market $k$ is $c_{n k}\left(q_{n k}\right)=4 q_{n k}^{2}+5, n=1,2, k=1,2$.

The demand functions at demand markets are $d_{1}(\rho)=400-10 \rho_{1}-2 \rho_{2}$ and $d_{2}(\rho)=400-10 \rho_{2}-2 \rho_{1}$.

Implementing the LQP-PC method for the example can yield the equilibrium solutions of the CLSC model with and without capacity constraints. The convergence criterion of the LQP-PC algorithm is set that the absolute value of difference of decision variables and Lagrange multipliers between two steps is lower than or equal to $10^{-8}$. Here we list and illustrate the results of the followed four cases.

Example 1: Set the risk-averse degree of the manufacturers $\lambda_{m}=0.3, m=1,2$. Investigate the impact of return rate on the transaction prices, transaction volumes and the profits of two types of suppliers, manufacturers, retailers and collectors under different product BOMs, as shown in Table 1. 


\begin{tabular}{|c|c|c|c|c|c|c|c|c|c|}
\hline & \multicolumn{3}{|c|}{$\beta_{1}=2, \beta_{2}=1$} & \multicolumn{3}{|c|}{$\beta_{1}=1, \beta_{2}=2$} & \multicolumn{3}{|c|}{$\beta_{1}=2, \beta_{2}=2$} \\
\hline & $\mu=0.4$ & $\mu=0.5$ & $\mu=0.6$ & $\mu=0.4$ & $\mu=0.5$ & $\mu=0.6$ & $\mu=0.4$ & $\mu=0.5$ & $\mu=0.6$ \\
\hline$q_{1 j_{1} m}^{r}$ & 0.6074 & 0.5728 & 0.5172 & 0.3148 & 0.2956 & 0.2656 & 0.5079 & 0.4952 & 0.4630 \\
\hline$q_{2 j_{2} m}^{r}$ & 0.3037 & 0.2864 & 0.2586 & 0.6295 & 0.5913 & 0.5312 & 0.5079 & 0.4952 & 0.4630 \\
\hline$q_{m}$ & 0.4930 & 0.5508 & 0.6099 & 0.5110 & 0.5685 & 0.6264 & 0.4123 & 0.4762 & 0.5460 \\
\hline$q_{m}^{u}$ & 0.1893 & 0.2644 & 0.3513 & 0.1962 & 0.2729 & 0.3608 & 0.1583 & 0.2286 & 0.3145 \\
\hline$q_{m n}$ & 0.2465 & 0.2754 & & & 0.2843 & & & 0.2381 & 0.2730 \\
\hline$q_{n k}$ & 0.2465 & 0.2754 & & 555 & 0.2843 & & 61 & 0.2381 & 730 \\
\hline$q_{i k}$ & & 0.1377 & & & 0.1421 & & 825 & 0.1190 & 638 \\
\hline$q_{i m}$ & 0.0947 & 0.1322 & & 0.0981 & 0.1364 & 0.1804 & 0.0792 & 0.1143 & 0.1573 \\
\hline$\rho_{k}$ & 33.2922 & 33.2874 & 33.2825 & 33.2908 & 33.2860 & 33.2811 & 33.2990 & 33.2937 & 33.2878 \\
\hline$\pi_{j_{1}}$ & 0.9068 & 0.7844 & 0.6025 & 0.0972 & 0.0622 & 0.0116 & 0.5740 & 0.5357 & 0.4432 \\
\hline$\pi_{j_{2}}$ & 0.0306 & 0.0051 & -0.0328 & 0.7908 & 0.6739 & 0.5055 & 0.4450 & 0.4131 & 0.3360 \\
\hline$\pi_{m}$ & 1.013 & 1.1051 & 1.1505 & 0.9988 & 1.0597 & 1.0731 & 0.6962 & 0.8143 & 0.9120 \\
\hline$\pi_{n}$ & 3.2858 & 5.2488 & 7.2952 & 3.8920 & 5.8585 & 7.8744 & 0.6023 & 2.7193 & 5.0865 \\
\hline$\pi_{i}$ & 0.0153 & 0.0703 & 0.1406 & 0.0202 & 0.0769 & 0.1487 & -0.0058 & 0.0434 & 0.1100 \\
\hline$\Sigma$ & 5.2516 & 7.2136 & 9.156 & 5.7990 & 7.7312 & 9.6133 & 2.3117 & 4.5258 & 6.8877 \\
\hline
\end{tabular}

Table 1. The Impact of Return Rate on The CLSC Network Equilibrium under Different Product BOMs

According to Table 1, it can be observed that no matter which kind of product BOM is, as the increase of the return rate, the quantities of raw materials produced by the two type suppliers decrease; on the contrary, the transaction volumes of EOL products between manufacturers and collectors, the quantity of EOL products used to remanufacture and the total transaction volumes of products (including new products and remanufactured products) between manufacturers and retailers increase. More concretely, as the return rate increases, the increased output of remanufactured products generated from more EOL products available for reuse is larger than the decreased output of new products due to the reduction of raw materials provided by the suppliers. The average production cost comes down as a result of the increase of the EOL products so that the manufacturers prefer to produce more products. Further, the retailers obtain more products from the manufacturers and sell them at a relatively lower price, which is benefit for the consumers at the demand markets. All the channel members and the whole CLSC can get more profits except the suppliers. Base on the above results, we can draw the conclusions that the increase of the return rate can reduce the input of raw materials, stimulate the transactions of the CLSC network and boost the economy, so it is accordance with the philosophy of the sustainable development. 
Example 2: This example is conducted from Example 1 as follows. We keep the data in Example 1 but set the maximal production capacity of the two-type suppliers. On this basis, we investigate the impact of return rate on the equilibrium of the CLSC network under different product BOMs, as shown in Table 2.

\begin{tabular}{|c|c|c|c|c|c|c|c|c|c|}
\hline & $\mu=0.4$ & $\mu=0.5$ & $\mu=0.6$ & $\mu=0.4$ & $\mu=0.5$ & $\mu=0.6$ & $\mu=0.4$ & $\mu=0.5$ & $\mu=0.6$ \\
\hline$q_{1 j_{1} m}^{r}$ & 0.5000 & 0.5000 & 0.5000 & 0.2500 & 0.2500 & 0.2500 & 0.5000 & 0.4952 & 0.4630 \\
\hline$q_{2 j_{2} m}^{r}$ & 0.2500 & 0.2500 & 0.2500 & 0.5000 & 0.5000 & 0.5000 & 0.5000 & 0.4952 & 0.4630 \\
\hline$q_{m}$ & 0.4058 & 0.4808 & 0.5896 & 0.4058 & 0.4808 & 0.5896 & 0.4058 & 0.4762 & 0.5460 \\
\hline$q_{m}^{u}$ & 0.1558 & 0.2308 & 0.3396 & 0.1558 & 0.2308 & 0.3396 & 0.1558 & 0.2286 & 0.3145 \\
\hline$q_{m n}$ & 0.2029 & 0.2404 & 0.2948 & 0.2029 & 0.2404 & 0.2948 & 0.2029 & 0.2381 & 0.2730 \\
\hline$q_{n k}$ & 0.2029 & 0.2404 & 0.29 & 0.2 & 0.2404 & 0.2948 & 29 & 0.2381 & 0.2730 \\
\hline$q_{i k}$ & 0.0812 & 0.1202 & 0.1769 & 0.0812 & 0.1202 & 0.1769 & 0.0812 & 0.1190 & 0.1638 \\
\hline$q_{i m}$ & 0.0779 & 0.1154 & 0.1698 & 0.0779 & 0.1154 & 0.1698 & 0.0779 & 0.1143 & 0.1573 \\
\hline$\rho_{k}$ & 33.2995 & 33.2933 & 33.2842 & 33.2995 & 33.2933 & 33.2842 & 33.2995 & 33.2937 & 33.2878 \\
\hline$\pi_{j_{1}}$ & 1.7524 & 1.5735 & 0.8781 & 0.3364 & 0.2977 & 0.1323 & 0.6144 & 0.5357 & 0.4432 \\
\hline$\pi_{j_{2}}$ & 0.2579 & 0.2127 & 0.0384 & 1.8261 & 1.6688 & 1.0052 & 0.4897 & 0.4131 & 0.3360 \\
\hline$\pi_{m}$ & 0.6735 & 0.8310 & 1.0718 & 0.6151 & 0.7445 & 0.9444 & 0.6735 & 0.8143 & 0.9120 \\
\hline$\pi_{n}$ & 0.3911 & 2.8738 & 6.5891 & 0.3911 & 2.8738 & 6.5891 & 0.3911 & 2.7193 & 5.0865 \\
\hline$\pi_{i}$ & -0.0075 & 0.0451 & 0.1308 & -0.0075 & 0.0451 & 0.1308 & -0.0075 & 0.0434 & 0.1100 \\
\hline$\Sigma$ & 3.0674 & 5.5361 & 8.7081 & 3.1612 & 5.6298 & 8.8019 & 2.1612 & 4.5258 & 6.8877 \\
\hline
\end{tabular}

Table 2. The Impact of Return Rate on the CLSC Network Equilibrium under Different Product BOMs with Production Capacity Constraints of Suppliers

In Table 2, comparing the equilibrium solutions between the first two symmetric product BOMs $\left(\beta_{1}=2, \beta_{2}=1\right.$ and $\left.\beta_{1}=1, \beta_{2}=2\right)$, we can find that with the symmetric capacity constraints, the production quantity of new and remanufactured products, the transaction volumes between adjacent echelons and the market prices under the two BOMs are identical when the same return rate is set. The profits of the retailers and the collectors are equal too. This is because the capacity constraints limit the supply of the suppliers, which, in turn, makes the quantity of the new products made by raw materials precisely be equal to 0.25 . Moreover, the same return rate under the two cases of BOMs corresponds to the same quantities of EOL products collected and remanufactured products. So there is no difference of transaction volumes between the retailers and the manufacturers, the collectors and the manufacturers, which further leads to the same pricing and profits of the retailers and the collectors in the two BOMs. The reason that the profits of the manufacturers and the suppliers are different in two BOMs lies in that the cost functions of the two-type suppliers are distinct.

For the last product $\operatorname{BOM}\left(\beta_{1}=2, \beta_{2}=2\right)$, when the return rate is relatively low $(\mu=0.4)$, the production capacity constraints limit the supply of raw materials; instead when the return rate is relatively high ( $\mu=0.5$ and $\mu=0.6$ ), the quantities of raw materials provided by the suppliers are equal to that without capacity constraints. It is because the manufactures have two different channels to meet the market demand in CLSC. If the EOL products available for remanufacturing are sufficient, the quantity of the raw materials purchased by the manufacturers need not be up to the maximum capacities of the suppliers. 
Example 3: This example is conducted from Example 1 as follows. We fix the return rate $\mu=0.5$, keep the other data in Example 1 but assume the two manufacturers are risk-averse. They are not only concerned with profit maximization but also risk minimization. Their risk functions are given by $r_{m}=\left(\sum_{n=1}^{N} q_{m n}-0.6\right)^{2}$. This risk measure can be explained as follows: the two manufacturers wish to increase the transaction volumes with the retailers in order to sell more products. On this basis, we investigate the impact of risk-averse degree of the manufacturer on the equilibrium of the CLSC network under different product BOMs, as shown in Table 3.

\begin{tabular}{|c|c|c|c|c|c|c|c|c|c|}
\hline & \multicolumn{3}{|c|}{$\beta_{1}=2, \beta_{2}=1, \mu=0.5$} & \multicolumn{3}{|c|}{$\beta_{1}=1, \beta_{2}=2, \mu=0.5$} & \multicolumn{3}{|c|}{$\beta_{1}=2, \beta_{2}=2, \mu=0.5$} \\
\hline & $\lambda_{m}=0.2$ & $\lambda_{m}=0.3$ & $\lambda_{m}=0.4$ & $\lambda_{m}=0.2$ & $\lambda_{m}=0.3$ & $\lambda_{m}=0.4$ & $\lambda_{m}=0.2$ & $\lambda_{m}=0.3$ & $\lambda_{m}=0.4$ \\
\hline$q_{1 j_{1} m}^{r}$ & 0.5775 & 0.5777 & 0.5780 & 0.2981 & 0.2982 & 0.2983 & 0.4990 & 0.4996 & 0.5001 \\
\hline$q_{2 j_{2} m}^{r}$ & 0.2887 & 0.2889 & 0.2890 & 0.5962 & 0.5963 & 0.5965 & 0.4990 & 0.4996 & 0.5001 \\
\hline$q_{m}$ & 0.5553 & 0.5555 & 0.5558 & 0.5733 & 0.5734 & 0.5735 & 0.4798 & 0.4804 & 0.4809 \\
\hline$q_{m}^{u}$ & 0.2665 & 0.2666 & 0.2668 & 0.2752 & 0.2753 & 0.2754 & 0.2303 & 0.2306 & 0.2308 \\
\hline$q_{m n}$ & 0.2776 & 0.2778 & 0.2779 & 0.2866 & 0.2867 & 0.2868 & 0.2399 & 0.2402 & 0.2405 \\
\hline$q_{n k}$ & 0.2776 & 0.2778 & 0.2779 & 0.2866 & 0.2867 & 0.2868 & 0.2399 & 0.2402 & 0.2405 \\
\hline$q_{i k}$ & 0.1388 & 0.1389 & 0.1389 & 0.1433 & 0.1433 & 0.1434 & 0.1199 & 0.1201 & 0.1202 \\
\hline$q_{i m}$ & 0.1333 & 0.1333 & 0.1334 & 0.1376 & 0.1376 & 0.1377 & 0.1152 & 0.1153 & 0.1154 \\
\hline$\rho_{k}$ & 33.2871 & 33.2870 & 33.2870 & 33.2856 & 33.2856 & 33.2855 & 33.2934 & 33.2933 & 33.2933 \\
\hline$\pi_{j_{1}}$ & 0.8005 & 0.8013 & 0.8022 & 0.0666 & 0.0667 & 0.0668 & 0.5470 & 0.5487 & 0.5504 \\
\hline$\pi_{j_{2}}$ & 0.0084 & 0.0086 & 0.0088 & 0.6886 & 0.6890 & 0.6895 & 0.4225 & 0.4239 & 0.4254 \\
\hline$\pi_{m}$ & 1.0290 & 1.0250 & 1.0211 & 0.9781 & 0.9756 & 0.9731 & 0.7526 & 0.7430 & 0.7335 \\
\hline$\pi_{n}$ & 5.4032 & 5.4113 & 5.4193 & 6.0221 & 6.0272 & 6.0321 & 2.8412 & 2.8600 & 2.8786 \\
\hline$\pi_{i}$ & 0.0720 & 0.0721 & 0.0722 & 0.0787 & 0.0787 & 0.0788 & 0.0447 & 0.0449 & 0.0451 \\
\hline$\Sigma$ & 7.3132 & 7.3184 & 7.3235 & 7.8341 & 7.8373 & 7.8404 & 4.6080 & 4.6206 & 4.6330 \\
\hline
\end{tabular}

Table 3. The Impact of Risk-averse Degree of the Manufacturers on the CLSC Network Equilibrium under Different Product BOMs

According to Table 3, it can be observed that as the risk-averse degree $\lambda_{m}$ increases, the production quantity of raw materials, new products and remanufactured products, the collection quantity of EOL products and the transaction volumes between adjacent echelons increase too. All the channel members and the whole CLSC can get more profits except the manufacturers. We can explain the results as follows: according to the equilibrium solutions in the absence of risk aversion in Table 1, it can be found that the optimal transaction volume of the products between the manufacturer and the retailer is lower than 0.3 under each product BOM when $\mu=0.5$ is set, so the transaction volume between one manufacturer and the two retailers is less than 0.6 . Therefore, based on the given risk functions, the manufacturers need to purchase more raw materials from the suppliers, buy-back more EOL products from the collectors and make more products to hedge the risk. The behaviors of the manufacturers make the transaction volumes of the CLSC network increase and improve the profits of the other members. However, for the manufacturer himself, there is a conflict between the two objectives of profit maximization and risk minimization. In other words, if the manufacturers can give up a part of interests, then the performance of CLSC will be better. 
Example 4: This example takes the two factors of risk aversion of the manufacturers and capacity constraints of suppliers into account. On this basis, we investigate the impact of riskaverse degree on the equilibrium of the CLSC network under different product BOMs, as shown in Table 4.

\begin{tabular}{|c|c|c|c|c|c|c|c|c|c|}
\hline & \multicolumn{3}{|c|}{$\begin{array}{c}\beta_{1}=2, \beta_{2}=1, \mu=0.5, C_{1}=0.5, \\
C_{2}=0.25\end{array}$} & \multicolumn{3}{|c|}{$\begin{array}{l}2, \mu=0.5, c_{1}=0.25, \\
C_{2}=0.5\end{array}$} & \multicolumn{3}{|c|}{$\begin{array}{l}2, \mu=0.4, C_{1}=0.5, \\
C_{2}=0.5\end{array}$} \\
\hline & $\lambda_{m}=0.2$ & $\lambda_{m}=0.3$ & $\lambda_{m}=0.4$ & $\lambda_{m}=0.2$ & $\lambda_{m}=0.3$ & $\lambda_{m}=0.4$ & $\lambda_{m}=0.2$ & $\lambda_{m}=0.3$ & $\lambda_{m}=0.4$ \\
\hline$q_{1 j_{1} m}^{r}$ & 0.5000 & 0.5000 & 0.5000 & 0.2500 & 0.2500 & 0.2500 & 0.4995 & 0.5000 & 0.5000 \\
\hline$q_{2 j_{2} m}^{r}$ & 0.2500 & 0.2500 & 0.2500 & 0.5000 & 0.5000 & 0.5000 & 0.4995 & 0.2500 & 0.2500 \\
\hline$q_{m}$ & 0.4808 & 0.4808 & 0.4808 & 0.4808 & 0.4808 & 0.4808 & 0.4803 & 0.4808 & 0.4808 \\
\hline$q_{m}^{u}$ & 0.2308 & 0.2308 & 0.2308 & 0.2308 & 0.2308 & 0.2308 & 0.2305 & 0.2308 & 0.2308 \\
\hline$q_{m n}$ & 0.2404 & 0.2404 & 0.2404 & 0.2404 & 0.2404 & 0.2404 & 0.2401 & 0.2404 & 0.2404 \\
\hline$q_{n k}$ & 0.2404 & 0.2404 & 404 & 0.2404 & 0.2404 & 0.2404 & 401 & 0.2404 & 0.2404 \\
\hline$q_{i k}$ & 202 & .1202 & 0.1202 & 0.1202 & 0.1202 & 0.1202 & 201 & 0.1202 & 0.1202 \\
\hline$q_{i m}$ & 0.1154 & 0.1154 & 0.1154 & 0.1154 & 0.1154 & 0.1154 & 0.1153 & 0.1154 & 0.1154 \\
\hline$\rho_{k}$ & 33.2933 & 33.2933 & 33.2933 & 33.2933 & 33.2933 & 33.2933 & 33.2934 & 33.2933 & 33.2933 \\
\hline$\pi_{j_{1}}$ & 1.6412 & 1.6412 & 1.6412 & 0.3178 & 0.3178 & 0.3178 & 0.5484 & 0.5530 & 0.5611 \\
\hline$\pi_{j_{2}}$ & 0.2297 & 0.2297 & 0.2297 & 1.7496 & 1.7496 & 1.7496 & 0.4237 & 0.4280 & 0.4361 \\
\hline$\pi_{m}$ & 0.7463 & 0.7463 & 0.7463 & 0.6435 & 0.6435 & 0.6435 & 0.7446 & 0.7300 & 0.7138 \\
\hline$\pi_{n}$ & 2.8738 & 2.8738 & 2.8738 & 2.8738 & 2.8738 & 2.8738 & 2.8569 & 2.8738 & 2.8738 \\
\hline$\pi \pi_{i}$ & 0.0451 & 0.0451 & 0.0451 & 0.0451 & 0.0451 & 0.0451 & 0.0449 & 0.0451 & 0.0451 \\
\hline$\Sigma$ & 5.5361 & 5.5361 & 5.5361 & 5.6298 & 5.6298 & 5.6298 & 4.6185 & 4.6298 & 4.6298 \\
\hline
\end{tabular}

Table 4. The Impact of Risk-averse Degree of the manufacturers on the CLSC Network Equilibrium under Different Product BOMs with Production Capacity Constraints of Suppliers

According to Table 4 , it can be observed that under the first two kinds of product BOMs $\left(\beta_{1}=2\right.$, $\beta_{2}=1$ and $\left.\beta_{1}=1, \beta_{2}=2\right)$, the equilibrium production and remanufacturing quantities, the equilibrium transaction volumes and the profits of various channel members don't vary with the change of the return rate due to the effect of the capacity constraints of the suppliers. Under the last product $\operatorname{BOM}\left(\beta_{1}=2, \beta_{2}=2\right)$, when $\lambda_{m}=0.2$, the optimal quantities of raw materials made by the suppliers don't reach the upper bound of their capacities; whereas as $\lambda_{m}$ continues to increase to 0.3 and 0.4 , the capacity constraints will take effect.

\section{Conclusions}

We study a CLSC network equilibrium problem considering two-type suppliers, the risk-averse character of the manufacturers and the capacity constraints of the suppliers comprehensively. Based on finite-dimensional variational inequality theory, we analyze the optimal behaviors of various channel members and establish the governing CLSC network equilibrium formulation. The LQP-PC algorithm is utilized to solve the variational inequality problem. Numerical examples are given to analyze the impact of return rate and risk-averse degree upon the network equilibrium under different BOMs. The results show that with the increase of return rate, the profits of various channel members and the performance of the CLSC system will improve. With the increase of risk-averse degree, the manufacturers will bear benefit losses. In other words, there is a contradiction between profit maximization and risk minimization for the 
manufacturers. Moreover, the economic behavior of the CLSC is likely to be limited by the capacity constraints of the suppliers.

In the future, we would like to extend our model to study the multi-period CLSC network equilibrium problem involving multi-type suppliers and risk aversion.

\section{Acknowledgment}

The work is supported by the National Natural Science Foundation, China (71202142).

\section{References}

Atasu, A., Guide, V.D.R., \& Wassenhove, L.N. (2008). Product Reuse Economics in Closed-Loop Supply Chain Research. Production and Operations Management, 17(5), 483-496. http://dx.doi.org/10.3401/poms.1080.0051

Chen, J.M., \& Chang, C.I. (2012). The co-opetitive strategy of a closed-loop supply chain with remanufacturing. Transportation Research Part E: Logistics and Transportation Review, 48(2), 387-400. http://dx.doi.org/10.1016/j.tre.2011.10.001

Debo, L.G., Toktay, L.B., \& Van Wassenhove, L.N. (2005). Market segmentation and product technology selection for remanufacturable products. Management Science, 51(8), 1193-1205. http://dx.doi.org/10.1287/mnsc.1050.0369

Ferguson, M.E., \& Toktay, L.B. (2006). The effect of competition on recovery strategies. Production and operations management, 15(3), 351-368. http://dx.doi.org/10.1111/j.19375956.2006.tb00250.x

Golinska, P., \& Kawa, A. (2011). Remanufacturing in automotive industry: Challenges and limitations. Journal of Industrial Engineering and Management, 4(3), 453-466. http://dx.doi.org/10.3926/jiem.2011.v4n3.p453-466

Guide, V.D.R., \& Wassenhove, L.N. (2006). Closed-Loop Supply Chains: An Introduction to the Feature Issue (Part 1). Production and Operations Management, 15(3), 345-350. http://dx.doi.org/10.1111/j.1937-5956.2006.tb00249.x

Hammond, D., \& Beullens, P. (2007). Closed-loop supply chain network equilibrium under legislation. European Journal of Operational Research, 183(2), 895-908.

http://dx.doi.org/10.1016/j.ejor.2006.10.033

He, B.S., Xu, Y., \& Yuan, X.M. (2006). A logarithmic-quadratic proximal prediction-correction method for structured monotone variational inequalities. Computational Optimization and Applications, 35(1), 19-46. http://dx.doi.org/10.1007/s10589-006-6442-4

Keeney, R.L., \& Raiffa, H. (1993). Decisions with multiple objectives: preferences and value trade-offs. London: Cambridge university press. 
Korpelevich, G.M. (1976). The extragradient method for finding saddle points and other problems. Matecon, 12, 747-756. http://ci.nii.ac.jp/naid/10017556617/

Majumder, P., \& Groenevelt, H. (2001). Competition in remanufacturing. Production and Operations Management, 10(2), 125-141. http://dx.doi.org/10.1111/j.1937-5956.2001.tb00074.x

Meng, Q., Huang, Y., \& Cheu, R.L. (2009). Competitive facility location on decentralized supply chains. European Journal of Operational Research, 196(2), 487-499.

http://dx.doi.org/10.1016/j.ejor.2008.03.030

Mitra, S., \& Webster, S. (2008). Competition in remanufacturing and the effects of government subsidies. International Journal of Production Economics, 111(2), 287-298. http://dx.doi.org/10.1016/j.ijpe.2007.02.042

Nagurney, A., Cruz, J., Dong, J., \& Zhang, D. (2005). Supply chain networks, electronic commerce, and supply side and demand side risk. European Journal of Operational Research, 164(1), 120-142. http://dx.doi.org/10.1016/j.ejor.2003.11.007

Nagurney, A., Dong, J., \& Zhang, D. (2002). A supply chain network equilibrium model. Transportation Research Part E: Logistics and Transportation Review, 38(5), 281-303. http://dx.doi.org/10.1016/S1366-5545(01)00020-5

Nagurney, A., \& Toyasaki, F. (2005). Reverse supply chain management and electronic waste recycling: a multitiered network equilibrium framework for e-cycling. Transportation Research Part E: Logistics and Transportation Review, 41(1), 1-28. http://dx.doi.org/10.1016/j.tre.2003.12.001

Örsdemir, A., Kemahlıoğlu-Ziya, E., \& Parlaktürk, A.K. (2014). Competitive quality choice and remanufacturing. Production and Operations Management, 23(1), 48-64. http://dx.doi.org/10.1111/poms.12040

Qiang, Q., Ke, K., Anderson, T., \& Dong, J. (2013). The closed-loop supply chain network with competition, distribution channel investment, and uncertainties. Omega, 41(2), 186-194. http://dx.doi.org/10.1016/j.omega.2011.08.011

Savaskan, R.C., Bhattacharya, S., \& Van Wassenhove, L.N. (2004). Closed-loop supply chain models with product remanufacturing. Management science, 50(2), 239-252. http://dx.doi.org/10.1287/mnsc.1030.0186

Savaskan, R.C., \& Van Wassenhove, L.N. (2006). Reverse channel design: the case of competing retailers. Management Science, 52(1), 1-14. http://dx.doi.org/10.1287/mnsc.1050.0454

Shi, J., Zhang, G., \& Sha, J. (2011). Optimal production planning for a multi-product closed loop system with uncertain demand and return. Computers \& Operations Research, 38(3), 641-650. http://dx.doi.org/10.1016/j.cor.2010.08.008

Wakolbinger, T., Toyasaki, F., Nowak, T., \& Nagurney, A. (2014). When and for whom would ewaste be a treasure trove? Insights from a network equilibrium model of e-waste flows. International Journal of Production Economics, 154, 263-273. 
Webster, S., \& Mitra, S. (2007). Competitive strategy in remanufacturing and the impact of take-back laws. Journal of Operations Management, 25(6), 1123-1140.

http://dx.doi.org/10.1016/j.jom.2007.01.014

Yang, G.F., Wang, Z.P., \& Li, X.Q. (2009). The optimization of the closed-loop supply chain network. Transportation Research Part E: Logistics and Transportation Review, 45(1), 16-28. http://dx.doi.org/10.1016/j.tre.2008.02.007

Zhu, X., \& Xu, X. (2012). An integrated optimization model of a Closed-Loop Supply Chain under uncertainty. Journal of System and Management Sciences, 2(3), 9-17. http://www.aasmr.org/jsms/Vol2/No3/JSMS_Vol2_No3_2.pdf

Zsidisin, G.A. (2003). Managerial perceptions of supply risk. Journal of supply chain management, 39(4), 14-26. http://dx.doi.org/10.1111/j.1745-493X.2003.tb00146.x

Journal of Industrial Engineering and Management, 2015 (www.jiem.org)

Article's contents are provided on a Attribution-Non Commercial 3.0 Creative commons license. Readers are allowed to copy, distribute and communicate article's contents, provided the author's and Journal of Industrial Engineering and Management's names are included. It must not be used for commercial purposes. To see the complete license contents, please visit http://creativecommons.org/licenses/by-nc/3.0/. 